SlavVaria 1/2021. 167-179

DOI: $10.15170 / S V .1 / 2021.167$

\author{
ИШТВАН НАДЬ \\ (Будапешт, Венгрия)
}

\title{
«Поэзия - уже перевод, с родного языка на чужой...» (Цветаева и Рильке)
}

Аннотация: Письмо Цветаевой Рильке о переводе поэзии является кредо Цветаевой-переводчика. Цветаева часто размышляет о своем языковом сознании. Она впервые комментирует перевод в своих письмах Райнер Мария Рильке. В них она развивает метафору «поэзия - это перевод», которая происходит из немецкой языковой игры „Dichten ist schon nachdichten”. Перевод возможен, потому что возможна поэзия. В одном из писем Рильке Цветаева пишет: „Dichten ist schon übertragen, aus der Muttersprache - in eine andere, ob französisch oder deutsch wird wohl gleich sein.” Писать стихи - это перевод с родного языка на другой.

В статье рассматривается, как Цветаева «делает один шаг в сторону „метафорической истины”».

Ключевые слова: стихия слова, национальность как от- и заключенность, метафорическая истина, поэзия как перевод

«Дорогой Райнер,

у Гёте где-то сказано, что на чужом языке нельзя создать ничего значительного, - я же всегда считала, что это неверно. (Гёте никогда не ошибается в целом, он прав в итоговом смысле, поэтому сейчас я не справедлива к нему.)

Поэзия - уже перевод, с родного языка на чужой - будь то французский или немецкий - неважно. Для поэта нет родного языка. Писать стихи и значит перелагать. Поэтому я не понимаю, когда говорят о французских, русских или прочих поэтах. Поэт может писать по-французски, но не быть французским поэтом. Смешно.

Я не русский поэт и всегда недоумеваю, когда меня им считают и называют. Для того и становишься поэтом (если им вообще можно стать, если им не являешься отродясь!), чтобы не быть французом, русским и т. д., чтобы быть - всем. Иными словами: ты - поэт, ибо не француз. Национальность - это от- и заключенность. Орфей взрывает национальность или настолько широко раздвигает ее предел, что все (и бывшие и сущие) заключаются в нее. И хороший немец - там! И - хороший русский!

Но в каждом языке есть нечто лишь ему свойственное, что и есть сам язык. Поэтому по-французски ты звучишь иначе, чем по-немецки, - 
оттого и стал писать по-французски! Немецкий глубже французского, полнее, растяжимее, темнее. Французский: часы без отзвука, немецкий более отзвук, чем часы (бой). Немецкий продолжает создаваться читателем - вновь и вновь, бесконечно. Французский - уже создан. Немецкий - возникает, французский - существует. Язык неблагодарный для поэтов - потому ты и стал писать на нем. Почти невозможный язык.

Немецкий - бесконечное обещание (тоже - дар!), но французский дар окончательный. Платен пишет по-французски. Ты («Verger») пишешь по-немецки, то есть - себя, поэта. Ибо немецкий ближе всех к родному. Ближе русского, по моему. Еще ближе.

Райнер, узнаю тебя в каждой строчке, но звучишь ты короче, каждая строка - усеченный Рильке, почти как конспект. Каждое слово. Каждый слог» (ЦВЕТАЕВА 1993-95: VII, 66).

По всей вероятности, мы начинаем понимать нечто существенное в литературе, когда мы начинаем думать о том, что принято обозначать словом «перевод». Перевод, как поэт говорит, одна из форм внимательного «слушания». Тот вопрос, что можно слышать в переводимом языке, важнее того, можно ли это сказать на том языке, на который мы переводим. Существует такое мнение, согласно которому основная проблема перевода не в том, чтобы переводчик как можно больше сохранил из своего языка, а в том, чтобы ему как можно больше удалось спасти из духа переводимого языка. Поэт говорит еще и то, что перевод является слухом зова. Когда мы переводим, мы переводим не слово, а того, кто слышит зов и подчиняется силе зова. В переводе мы переставляем себя в секретности возвращения. Перевод - повелительное наклонение, случай обращения.

«Несколько писем Райнер Мария Рильке» привлекает к себе внимание по причине сильной метафоричности. Марина Цветаева в своем эссе обращает внимание на сущность перевода, но будучи поэтом, она делает это отнюдь не с научной точки зрения, то есть с точки зрения поэтики или риторики, а призывает на помощь метафору, она ожидает от нее, чтобы выяснился скрытый смысл перевода. Мы могли бы сказать и так вслед за Рильке, что она как поэт делает один шаг в сторону «метафорической истины».

«А сегодня мне хочется, чтобы Рильке говорил - через меня. Это, в просторечии, называется перевод. (Насколько у немцев лучше - nachdichten! Идя по следу поэта, заново прокладывать всю дорогу, которую прокладывал он. Ибо, пусть - nach (вслед), но - dichten! - то, что всегда заново. Nachdichten - заново прокладывать дорогу по мгновенно зарастающим следам.) Но есть у перевода еще другое значение. Перевести не только на (русский язык, например), но и через (реку). Я Рильке перевожу на русскую речь, как он когда-нибудь переведет меня на тот свет.

За руку - через реку.» (ЦВЕТАЕВА 1993-95: V, 322). 
В адресованном А. А. Тесковой, чешской писательнице письме мы встречаем аналогичную интерпретацию перевода: «Убеждена еще, что когда буду умирать - за мной придет. Переведет на тот свет, как я сейчас перевожу его (за руку) на русский язык. Только так понимаю - перевод» (ЦВЕТАЕВА 1993-95: VI, 375).

Многозначительный немецкий глагол «übersetzen» имеет метафизический резонанс, и это замечает Цветаева. Пока нам хотелось бы только указать на метафизическую перспективу процитированного текста, которую открывают слова дорога, река и смерть. Метафора видимо помогает понять что-нибудь в коннотативном значении слова. Метафорический смысл нуждается в герменевтической интерпретации. Тропологическая структура метафоры как языкового явления является совместным присутствием «очевидного» (денотативного) и «скрытого» (коннотативного). Если в метафоре идет речь о поэтической истине, источник которой находится в языке, тогда метофорическое значение дороги приводит нас к вопросу «видимого» и/или «невидимого».

«Правда поэта - тропа, зарастающая по следам. Бесследная бы и для него, если бы он мог идти позади себя.» (ЦВЕТАЕВА 1993-95: V, 365).

Это предложение Цветаевой приближает нас к тому утверждению философа Хайдеггера, что язык делает что-то очевидным, освещает и в то же время покрывает что-то в самом бытии. Метафора дороги в контексте умершего Рильке является отнюдь не случайной. Значение «дороги» в том, что душа мертвого человека движется по потустороннему пути, смотри немецкое слово Spur и также немецкое spiro (дышать) (> „душа”). Значение «дороги» связано со значением «звука» в мифологической символике индоевропейских языков...

Если языковая память вызвала метафору дороги из-под глубины бессознательного, и в таком смысловом контексте как перевод - язык поэзия (см. «Несколько писем Райнер Мария Рильке» и на несколько лет позже «Искусство при свете совести»), Цветаева ходит два раза вокруг многозначительного глагола переводить - первый раз в письме к Тесковой (за руку перевести его к русскому языку), а второй раз (за руку перевести ее на потусторонний берег), тогда это показывает, что данная метафора (или метафорическая аттракция, если включить сюда и метафору воды) несомненно имела эвристическое значение для Цветаевой.

В окончательном варианте «Несколько писем Райнер Мария Рильке» сохраняется метафорическая инвенция, которую Цветаевой подсказало амбивалентное значение глагола «переводить». Однако закрытая в «навязчивую» метафору, мифопоэтическая роль уже однозначно показывает в сторону мертвого Рильке как управляющего душой (Seelenführer).

Когда Цветаева называет Рильке как Seelenführer и все это связывает с проблематикой перевода, тогда она исходит из двойного значения немецкого глагола übersetzen, ибо в зависимости от того, на что падает 
ударение, на глагол или на приставку, значение в основном меняется. Über-setzen (переводить с одного языка на другой, с иностранного на родной или наоборот), однако über-setzen означает переводить наше существо в другой мир. Важно отметить, что немецкий übersetzen первоначально означает «перебрасываться через реку» (,„über ein Wasser bringen”). Пишущая по-русски Цветаева, по крайней мере здесь, в связи с Рильке, думает по-немецки и ведет слово к его изначальному значению. Поэтическая интерпретация глагола переводить (я как переводчица, Рильке Seelenführer) легитимируется этимологией, потому что этимологическим родственником слова переводчик является проводник.

Если мы принимаем во внимание то обстоятельство, что Гермес (бог дорог) выполняет двойную функцию в греческой мифологии - функцию проводника душ и вестника богов, тогда несомненно Рильке, наряду с первой функцией, выполняет и вторую в личной мифологии Цветаевой. И если мы думаем о том, что по Хайдеггеру герменевтика означает не только интерпретацию, а прежде всего сообщение и извещение, тогда Цветаева проецирует Рильке на мифологический образ Гермеса, и этим самым она ставит Рильке в положение герменевтического собеседника, с которым она меняется мнениями о секрете языка и мастерства. Они делают то, о чем пишет Хайдеггер, они слышат, как язык говорит.

Речь идет о проблеме языка, о языковости перевода.

Мы находим несколько мест в переписке Цветаевой и Рильке, где слушание языка приводит их к оригинальному смыслу слова. Языковое поведение Цветаевой, которое возвращается к источнику языка, движимо герменевтикой.

Мы читаем у Хайдеггера в «Бытии и времени»:

«Слышание конститутивно для речи. И как словесное озвучание основано в речи, так акустическое восприятие в слышании. Прислушивание к ... есть экзистенциальная открытость присутствия как событие для других. Слышание конституирует даже первичную и собственную открытость присутствия для его самого своего умения быть в качестве слышания голоса друга, которого всякое присутствие носит с собой. Присутствие слышит, потому что понимает. Как понимающее бытиев-мире с другими оно „послушно” соприсутствию и себе самому и в этом послушании к ним принадлежно» (ХАЙДЕГГЕР 2002: 163).

Мы имеем совсем другую модель мира и человека в зависимости от того, какую из этих двух существенных перцептивных аналогий понимания и значения предпочитает художественное смысловое образование: зрение ли, которое в «Антропологической философии» Павла Флоренского получает однозначно объективную, внешнюю, пассивную роль, или слух, в котором, наоборот, играют руководящую роль субъективность, внутреннее и активное. Флоренский признает герменевтическое приоритет слуха над зрением, когда он пишет 
следующее: «Вне всякого сомнения, тем или иным способом, но звук доходит до нашего уха и приходит к нашему сознанию, как одно индивидуальное целое, раз только он был произведен таковым» (ФЛОРЕНСКИЙ 2000: 235).

Известно высказывание Цветаевой, в котором она говорит о разнице между своей поэзией и поэзией Пастернака, точнее о том, в чем расходится их поэтика: «... Пастернак, в стихах, видит, а я слышу» (ЦВЕТАЕВА 1993-95: VI, 366). Продолжая это основополагающее определение, мы можем к нему добавить, что поэт Цветаева открывает новое измерение в языке, измерение глубины: «Поэт - издалека заводит речь. // Поэта - далеко заводит речь» (ЦВЕТАЕВА 1993-95: II, 184). Проблему «издалека - далеко» в связи с языком Гадамер оценивает следующим образом: «... непосредственность нашего видения мира и самих себя - непосредственность, за которую мы упорно держимся, - сберегается языком и находится в его распоряжении, поскольку мы, конечные существа, всегда приходим издалека и идем далеко. В языке становится видимой та действительность, которая возвышается над сознанием каждого отдельного человека» (ГАДАМЕР 1988: 520). Исследованный в контексте бытия язык, который является краеугольным камнем персональной поэтики Цветаевой, открытостью слова обращается в сторону человека: она понимает язык сущностью бытия за другого.

Вряд ли она преувеличивает свою духовно-психологическую установку, когда замечает о себе: «Вообще, из всех пресловутых пяти чувств, знаю только одно: слух. Остальных - как бы не бывало и - хоть бы не было!» (ЦВЕТАЕВА 1993-95: VII, 31). Она переносит поэтику звучащего слова как творческую силу и на личные отношения: «У Вас есть слух на меня, на мое.» - пишет П.П. Сувчинскому (ЦВЕТАЕВА 1993-95: VI, 315). Так как слух у нее имеет глубинное измерение, поэтому она способна услышать голос Другого.

Для Цветаевой в существенном понимании языка помогает раскрывающий самого себя язык, в данном случае немецкий. Она слышит то, что слово говорит. Цветаева, как об этом уже шла речь, слушает язык, она вслушивается в него. Рильке в одном написанном своей секретарше (N. Wunderli-Volkart) письме делает наглядным отношение человека и языка, то, что человек принадлежит к языку, с помощью немецкого глагола hören и его дериватами.

«Я ничего не хочу иметь [...], лишь быть в вещах, прозревать их [...], не так, как Гёте (глубоким взором!), слышать вещи как Рильке (глубоким слухом - трубой (По-немецки: hören - horchen - gehorchen - gehören.) В них вслушиваться, их слушаться, им принадлежать, быть вещами.» читаем у Цветаевой. (НЕБЕСНАЯ 1992: 190).

Переписка Цветаевой и Рильке единственна в своем роде относительно семиотической и герменевтической «поездки». Точнее, относительно по- 
ездки в языковом пространстве, в котором перестает существовать дуальная оппозиция собственного и чужого, обобщенно человеческого $и /$ или национального. На их место попадает духовная встреча, диалог (Ge-spräch).

Возвращаемся к ситуативной метафоре, в которой разные вещи находятся рядом друг с другом: перевод как письменный акт и смерть как экзистенциально-онтологическое событие человеческой жизни. («Я перевожу Рильке на русский язык таким образом, как он переведет меня на тот свет. Рука об руку».) Метафора создается фантазией, и она ирреальна по своей модальности, и мы чувствительны к ней потому, что присутствуют рядом разные вещи, а именно перевод как литературная деятельность и вызванный фантазией образ смерти. Потусторонняя встреча, таким образом, становится частью индивидуальной мифологии Цветаевой. Что и как метафоризуется, это зависит от того, насколько метафора важна для поэта и какое место она занимает в семантическом мире поэта. Человекпоэт осознается в бытии как окликнутый.

Цветаева во время переписки с Рильке, но и попозже, читает «Дуинские элегии» и стихи сборника «Сонеты к Орфею». Ее встреча с РилькеОрфеем есть встреча со звуком, встреча со смертью. Это снова предупреждает нас о том, что в творческом мире Цветаевой и в её герменевтической системе ценностей две вещи неразрывно связаны друг с другом: писать стихи и умереть.

Всюду, где в переписке заходит речь о звуке и слухе, чувствуется ее встреча со сборником «Сонеты к Орфею». Рильке для Цветаевой не есть интертекст, а текстовая память, память о тексте.

Когда Цветаева воспринимает перевод, как разговор через другого человека («чтобы Рильке говорил через меня»), тогда она воспринимает перевод как текст-палимпсест, в результате чего из двух голосов двух поэтов будет один голос. Когда Цветаева и Рильке обращаются к трехпространственной архитектуре поэтического слова, тогда они естественным образом актуализуют старую этимологию слова dichten (architektura), которую оба воспринимают положительно. Немецкое dichten (писать стихи) этимологически восходит к слову tichton, tiktousz (по-гречески создать), родственное со словом архитектура (пространство), которое заключает в себе исторически значение слова создать.

Два примера для того, насколько глубоко они чувствовали пространственное значение слова. Рильке пишет Цветаевой:

«... я пишу как ты, и подобно тебе спускаюсь из фразы на несколько ступенек вниз, в полумрак скобок, где так давят своды и длится благоуханье роз, что цвели когда-то. Марина: я уже так вжился в твое письмо. [...] Вторую ночь вчитываюсь в твоего «Орфея». (Твой «Орфей» - страна...») - ответ Цветаевой Рильке (ПИСЬМА 1990: 90, 93). 
Интересно, что Рильке переводит «язык» языка на «язык» литературы. Его чтение вполне по праву можем назвать архитектурным, пространственным.

Мы близко подошли к тому, как понимала перевод Цветаева. Если поэт переводит поэта, то это «голос одного поэта голосом другого поэта», то есть это речь через другого. Новый герменевтический парадокс заключается и в том, о чем она пишет Рильке: «Как жаль, что ты не можешь меня читать! Я перед тобою - глухонемая (собственно, не глухая - немая!)» (ЦВЕТАЕВА 1993-95: VII, 73).

Следовательно, кого не читают, тот осужден на немоту. Цветаева хочет, чтобы ее послушали. Но немой текст будет говорить только в том случае, если читатель придает ему свой голос. В литературе единственно стихотворный текст способен достичь того, чтобы чужой текст заговорил как свой текст. Лирика - такой дискурс, который прекращает расстояние между своим и чужим, «Я» и «Другим». Стихотворение не может существовать без того, кому оно адресовано. «Голос» текста (в герменевтике - требование текста) читатель усваивает благодаря тому, что передает ему свой голос.

В адресованном Рильке письме от 6 июля 1926 года она также пишет о проблематике перевода. Здесь Цветаева поднимает такие точки зрения, которых она раньше не касалась. Точнее, в то время как раньше перевод она интерпретировала в свете метафоры, здесь она исследует одни языки, потенциальную выразительную силу некоторых национальных языков.

Ответное письмо Рильке 28 июля 1926 года:

«Каждый раз, когда я пишу тебе, я хочу писать как ты, высказать себя по-твоему, при помощи твоих невозмутимых и все же таких волнующих средств. Как отражение звезды твоя речь. Марина, когда оно появляется на поверхности воды и, искаженное, встревоженное водою, жизнью воды, струями ее ночи, ускользает и возникает снова, но уже на большей глубине, как бы сроднившись с этим зеркальным миром, и так после каждого исчезновения: все глубже в волнах!» (ПИСЬМА 1990: 190).

Процитированное выше, написанное Рильке письмо («А сегодня мне хочется, чтобы Рильке говорил - через меня...) - одно из тех проявлений, в которых Цветаева как поэт разделяет свои взгляды с поэтом Рильке о различном статусе «родного» и иностранного языков, оригинального и переводного текстов. Её опыт в связи с немецким и французским языками заслуживает внимания потому, что и в этом случае она высказывается как поэт.

Несомненно и то, что Цветаева оценивает противостояние родного и иностранного языков не по общепринятому мнению, а с особенной точки зрения - поэта, пишущего стихи. Отнюдь не поразительно, если поэт, пишущий стихи, - независимо от своей национальной принадлежности считает своим родным языком именно поэзию, - то есть, если поэт пишет 
стихи, то каждый поэт пишет на своем родном языке, на языке поэзии. Значит, существует один не виртуальный, а действительный, реальный язык, родной язык каждого поэта, по отношению к которому выступление на любом национальном языке (национальная поэзия) - «уже перевод с родного языка на иностранный». Несомненно, Цветаева употребляет уже и само слово перевод не в обычном смысле, но уже и здесь следует отметить, что в контексте всего письма открывается такая точка зрения, которая релевантна и для теории перевода, которой немецкий философ, Вальтер Беньямин, посвятил целую статью, под заглавием «Задача переводчика» (в сборнике автора Ангелус Новус).

Значит, поэзия является переводом с родного языка поэта на любой национальный как чужой язык. Из этого заключения невольно возникают следующие вопросы. Кто есть переводчик? C какого языка он переводит? Этот родной язык существует только виртуально или действительно как текст (ведь переводить можно только текст)? Или написанное на национальном языке стихотворение уже есть перевод, поскольку (несколько указаний на это мы находим у Цветаевой) и поэзия уже перевод: с языка бытия на язык поэзии, и в этом смысле поэт завладевает бытием таким образом, что его переводит на родной язык, то есть пишет стихи? Наконец, поэзия как перевод - такое состояние, которое предполагает плодотворное напряжение между своим и чужим, где «родной язык» и «чужой язык» меняются местами? (Смотри письмо Цветаевой Рильке в начале нашей статьи.)

Высказывание Гёте («на чужом языке нельзя создать ничего значительного») на основе вышесказанного можно понимать двояким образом, в зависимости от того, что понимать под родным языком, и что под чужим. Гёте, очевидно, понял это таким образом: если поэт пишет не на своем родном языке (например немецкий поэт не по-немецки, а на каком-либо другом языке), однако Цветаева переворачивает отношение, поскольку она квалифицирует заговаривание на национальном языке как чужое, не на родном языке реализованное. Мы имеем дело с довольно парадоксальной вещью, поскольку «родной язык» поэта есть поэзия как инвариантный текст, а тексты на национальном языке являются его вариантами, которые воплощаются в переводах. «Поэт может писать пофранцузски, но не быть французским поэтом»!» - читаем у Цветаевой, что следует понимать так, что нет французского, немецкого, или например русского поэта, а есть - только поэт, который пишет на какомто национальном языке, однако это уже перевод.

В этом случае мы можем рискнуть вывести два предположения, а именно: с одной стороны, что понятая Цветаевой поэзия как родной язык поэта - не что иное, как то, что В. Беньямин назвал в упомянутой статье «чистым языком», а с другой, это совпадает с тем, что немецкий автор сказал о хорошем переводе. 
Поскольку речь идет о переводе, нельзя обойти вопрос переводимости, который Цветаева понимает и интерпретирует также на двух уровнях, а Беньямин апострофирует как теоретическое ключевое понятие.

Далее попытаемся восстановить те места из статьи Беньямина, которые, по нашему мнению, являются очевидными точками соприкосновения между концепцией перевода философа и поэта, в более широком смысле, между их пониманием языка. Случаем переводимости в языковом и лингвистическом смысле является то, если два языка как два лингвистических универсума показывают соответствия и расхождения (как Цветаева пишет: «иные вещи на ином языке не мыслятся».) В более широком онтологическом смысле переводимость оказывается ответом на вопрос «почему нужно и почему можно писать стихи?»

По Беньямину, перевод хорош в том случае, если в нем отзвучивается оригинальный язык. Несомненно, Беньямин говорит не о сообщении как о процессе и не о содержании, а о языке как о медиуме. Иначе говоря, в переводе каким-то образом должны отражаться языковость оригинального языка, то есть «чистый язык», стихотворение, написанное на национальном языке, должно репрезентатировать языковость поэзии. Через стихотворение как медиум, как трансляционную среду должны просвечиваться онтологическая и языковая сущность.

Если «перевод» соответствует этому требованию, в этом случае стихотворение имеет ценность. Носителем ценности оказывается язык, все зависит от него, следовательно, чем менее сообщителен с точки зрения содержания виртуальный текст, написанный на родном языке поэзии, иначе говоря, чем более является объектом сообщения язык поэзии, тем более он переводим. В этом смысле каждое стихотворение - в зависимости от его ценности и «достоинства» - является изображением и интерпретацией языковости родного языка. Говоря словами Беньямина - освобождением заключенного в поэзию «чистого языка». Придерживаясь немецкоязычной понятийной дистинкции Цветаевой, мы можем сказать, что «родной язык» принадлежит понятийному кругу dichten, а перевод nachdichten. Существует один большой виртуальный текст, это «поэзия», которая так или иначе, хорошо или плохо реализуется в написанном на национальном языке. Что говорит Беньямин о «настоящем переводе», то, можно сказать, без остатка действительно для написанной на национальном языке настоящей поэзии. Настоящий перевод прозрачен, не покрывает оригинальный текст, наоборот, обеспечивает то, чтобы чистый язык проникал в перевод.

Немецкий автор Рудольф Паннвиц говорит о том, что переводчики, даже самые лучшие, исходят из неверного основного положения, потому что они хотят подчинить перевод немецкому языку, вместо того, чтобы сделать немецкий текст в индийский, греческий, английский. Основная ошибка переводчика в том, что он сохраняет случайное состояние своего 
языка вместо того, чтобы допустить реализоваться влиянию иностранного языка. Переводчик, если он переводит из далекого языка, должен вернуться к самым далеким, древним элементам языка, туда, где слово, образ и звук представляют собой единство. Переводчик должен расширить и углубить свой язык чужим языком.

Если до сих пор шла речь об оригинальном языке и переводе, то есть о произведении, особенно о языке как об объекте, в дальнейшем приходится говорить о субъекте письма, а также о релевантном и иррелевантном характере национальной принадлежности. Цветаева подчеркивает, кто пишет стихи, тот является прежде всего поэтом («ты поэт, ибо не француз»), он должен соответствовать универсальным и обобщенным поэтико-языковым требованиям и системе ценностей, и только после этого может идти речь о национальной принадлежности, то есть о том, на каком языке написано произведение.

Орфей может быть прообразом, архетипом поэта, потому что для него иррелевантно, на каком языке говорит стихотворение, автором которого оказывается он: он говорит на языке поэзии, который не знает национальных границ. Поэтому и может писать Цветаева, что национальная принадлежность одновременно «ис- и включенность», исключенность из универсального и включенность в национальное. Негативная коннотация этой противоречивой и парадоксальной ситуации, если «включенность» в национальное сопровождается уменьшением качества и системы ценностей, и не их «увеличением». Однако «ис- и включенность» в этом отношении уже не отрицательное, а - опять же благодаря языку - положительное и предпринимаемое для поэта. Но об этом идет речь в дальнейшем, теперь стоит остановиться на вопросе «национальной принадлежности», тем более, что это касается того вопроса, насколько Цветаева русская, у которой много таких авторефлектирующих замечаний, которые, пожалуй, однозначно являются отрицанием ее национальной принадлежности.

«О русском русле... Русская я только - через стихию слова. Разве есть русские (французские, немецкие, еврейские и пр.) чувства? Просторы? ... Есть чувства временные (национальные, классовые), вне-временные (божественные: человеческие) и до́-временные (стихийные). Живу вторыми и третьими. Но дать голую душу - без тела - нельзя, особенно в большой вещи. Национальность - тело, т.е. опять одежда. Прочтите Царь-Девицу настаиваю... Но и Греция, и Россия - тело, т.е. одежда. Вы не любите одежды - согласна - сдерите ее и увидите суть. Это (в Царь-Девице), сделал пока один Борис Пастернак. - «На Вашу вещь не польстится иностранец, в ней ни опашней, ни душегреек, ничего русско-оперного, в ней человеческая душа, это иностранцу не нужно» (НЕИЗДАННОЕ 1997: 184). 
Отрицание национальных чувств (вообще «национальной принадлежности») в том смысловом контексте, в котором идет речь о языковом образе мира, больше чем сомнительно, потому что примеры Цветаевой говорят о том, о чем и когнитивное языкознание: значение как таковое, не только антропоцентрично, но и этноцентрично. Избранный текстовой фрагмент основывается на очевидном противостоянии антропоцентризма и этноцентризма, вследствие чего мы сами не знаем, насколько мы можем ему верить.

Если вглядеться в него более основательно, то мы встретимся со следующими противоречиями: Цветаева здесь говорит о «русском русле» своего творчества, между прочим с характерной для нее страстностью, но в то же время ее аргументация основывается на прагматических и реальных лингвистических соображениях. Между тем как она различает временное, вневременное и до-временное: она включает себя во время, добавим, в историческое время - с одной стороны, а с другой - она связывает язык не с исторической культурой, а с природной. Вечнобезвременная душа, имеющая положительную ценность, противостоит «телу», означающему национальную принадлежность. Цветаева как поэт утверждает, что она живет с вневременным и до-временным, а с другой стороны, она признает, что дать голую душу - без тела - нельзя. Следует отметить, для Цветаевой важнее постановка вопроса, чем примирение противоречий, и это свидетельствует о том, что Цветаева предрасположена ко всему, что в языке национальное, этноспецифическое. Вечно-безвременная душа противостоит означающему национальную принадлежность телу таким образом, что предыдущая имеет положительную ценность, в то же время «Царь-Девица» есть очень даже русская, прямо до разумной, звуковой, поэтической оформленности. Цветаева утверждает, что она живет с вневременным и довременным, с другой стороны, она признает и национальное.

По первому чтению вроде бы невероятно, что Цветаева, которая так чувствительна к этноспецифическим особенностям языка («иные вещи на ином языке не мыслятся»), и творчество которой описуемо и интерпретируемо со стороны русскоязычной картины мира, спрашивает следующее: «Разве есть русские (французские, немецкие, еврейские и пр.) чувства?» Это спрашивает та самая Цветаева, которая знает как будто все трепеты русского эмоционального мира и которая в одном месте говорит о «русской совести». Некоторые лингвисты считают, что этноспецифические особенности характерны не только для мышления, но и для эмоционального мира. Лингвист Анна Вежбицкая исходит из того, что каждый язык создает свой «семантический универсум» (ВЕЖБИЦКАЯ 1997: 298). Не только мысли можно думать, но и чувства чувствовать в одном языке, а в другом нет. Короче говоря, есть понятия, которые основополагающие для одной языковой модели, а в другой отсутствуют. 
В самом деле, Цветаева не отрицает бытие «национальных» (этноспецифических) чувств, а таким образом осуждает их, какое место они занимают и какую роль выполняют в органической культуре бытия. Из процитированных строк однозначно выясняется, что она воспринимает своими в иерархии чувств вневременные, божественные: человеческие чувства и довременные, элементарные чувства. И то не поразительно, что она ставит доисторические элементарные чувства на вершину иерархии, ведь элементарная сила воспринятого как природа языка есть каждодневный опыт и ссылка на ее аргументы. В отличие от Мандельштама, она воспринимает язык как природный мир. Нельзя пройти без слов и мимо того, что Цветаева употребляет для характеристики национальных и классовых чувств прилагательное временный, которое в зависимости от ударения позволяет два прочтения, то есть не постоянный и связанный со временем. Индуцированные национальной и классовой принадлежностью чувства она причисляет к миру временных чувств.

«Поэтому по-французски ты звучишь иначе, чем по-немецки, - оттого и стал писать по-французски!» - читали в письме Цветаевой. Цветаеву занимают прежде всего вопрос языкового индивидуального и языкового особенного, а это дает о себе знать в том приключении, что немецкий поэт Рильке начинает писать по-французски. Если мы думаем о том, что в системе Цветаевой слух и звучание являются смысловыми факторами, тогда звучание по другому («по-французски ты звучишь иначе») открывает новые аспекты личности и личностности. Значит, когда Рильке начинает писать по-французски, он показывает свое новое я, потому что его вписанное во французский язык отличается от того, что есть написанное я пишущего по-немецки Рильке.

Когда Цветаева, переводящая на немецкий и французский языки и свободно пишущая на двух языках, сравнивает два упомянутых языка, тогда она вопреки всему своему субъективизму (что «в-слушивает» в один и другой язык) поднимает ряд психологических и философских точек зрения, которые, несомненно, могут помочь в подходе к двум языкам.

Само собой разумеется, эту картину определяют такие, через поколения реализуемые, точки зрения теории и истории культуры, а также точки зрения характерологии нации, которые индуцированы немецкой философией, французским рационализмом и общепринятыми мнениями о двух народах.

Традиционную оппозицию немецкого иррационализма и французского рационализма можно услышать в том сравнении, согласно которому немецкий дух «глубже» и «темнее» французского. Сравнение с часами только еще заостряет разницу и оппозицию, когда она апострофирует французский язык как часы без отзвука, а немецкий скорее всего как отзвук (который отзвучивается в душе воспринимающего читателя). Поэ- 
тому и может писать Цветаева, что немецкий язык создается читателем, то есть он обеспечивает более значительное пространство для сотрудничества читателя (герменевтическая точка зрения), чем французский. Она противопоставляет «возникающий» немецкий язык «существующему» французскому, предполагая, что предыдущий создает более солидное пространство для писателя, чем французский. Если Рильке пишет пофранцузски, на этом «почти невозможном языке», тогда это означает, что французский язык для него является вызовом. А писать по-немецки означает: «писать самого себя». Конечный вывод Цветаевой: «немецкий ближе всех к родному, то есть к языку поэзии, к „чистому языку”». Рильке в письме от 17 мая 1926 года говорит об «общем» языке, к которому русский стоит «совсем близко» (предполагается, Цветаева указывает на это, когда замечает, что немецкий ближе стоит к «родному», даже ближе, чем русский): «Каждый язык - один язык» (НЕБЕСНАЯ 1992: 74).

\section{Литература}

ВЕЖБИЦКАЯ А. (1997) Язык, культура, Познание. Москва, 1997.

ГАДАМЕР Х.-Г. (1988) Истина и метод. Основы философской герменевтики. Москва: «Прогресс», 1988.

ЦВЕТАЕВА М. (1993-95) Собрание сочинений: В 7 томах. Москва: Эллис Лак, 1993-1995.

ПИСЬМА (1990) Райнер Мария Рильке. Борис Пастернак. Марина Цветаева. Письма 1926 года. Москва: «Книга», 1990.

НЕБЕСНАЯ (1992) Небесная арка. Марина Цветаева и Райнер Мария Рильке. Санкт-Петербург: «Акрополь», 1992.

НЕИЗДАННОЕ (1997) Марина Цветаева. Неизданное. Сводные Тетради. Москва: Эллис Лак, 1997.

ФЛОРЕНСКИЙ П. (2000) Сочинения: В 4 тт. Т. 3 (1). Москва, 2000.

ХАЙДЕГГЕР М. (2002) Бытие и время. Санкт-Петербург: «Наука», 2002.

Poetry itself is translation from the mother tongue into another language... Cvetaeva's letter to Rilke about the translation of poetry is Cvetaeva's credo of translation. Cvetaeva constantly reflects on her own linguistic consciousness. The first extensive set of commentaries on translation appears in the poet's correspondence with Rainer Maria Rilke. Cvetaeva developed the methaphor of "writing poetry as translating" inspired by wordplay in German: „Dichten ist schon nachdichten”. Translation is possible, because poetry is possible. Cvetaeva advocates an artistic, hermeneutically open approach to translation. Cvetaeva wrote in a letter to Rainer Maria Rilke: „Dichten ist schon übertragen, aus der Muttersprache - in eine andere, ob französisch oder deutsch wird wohl gleich sein." Writing poetry is in itself translating, from the mother tongue into another language.

Keywords: essence of a word, nationality as disconnect and confinement, metaphorical truth, poetry as translation 